\title{
Non-parasitic Splenic Cyst
}

\author{
Anahita Sadeghi ${ }^{1}$, Zeinab Naderpour ${ }^{2}$, Mahbube Ebrahimpur ${ }^{2, *}$, Hiva Saffar ${ }^{3}$
}

1. Assistant Professor of Internal Medicine, Digestive Disease Research Center, Digestive Disease Research Institute, Tehran University of Medical Sciences, Tehran, Iran

2. Assistant Professor of Internal Medicine, Department of Internal Medicine, Shariati Hospital, Tehran University of Medical Sciences, Tehran, Iran

3. Associate Professor of Anatomical and Clinical Pathology, Department of Pathology, Shariati Hospital, Tehran University of Medical Sciences, Tehran, Iran

\section{* Corresponding Author:}

Mahbube Ebrahimpur, MD

Department of Internal Medicine, Shariati Hospital, Tehran University of Medical Sciences, Kargar Shomali Avenue, Tehran, Iran

Tel: + 982184902152

Fax: + 982184902366

Email: mahbube10183@gmail.com

Received: 22 Jun. 2017

Accepted: 08 Sep. 2017
Please cite this paper as:

Sadeghi A, Naderpour Z, Ebrahimpur M, Saffar H. Non-parasitic Splenic Cyst. Middle East J Dig Dis 2017;9:242-243. doi: 10.15171/mejdd.2017.81.

A 19-year-old woman presented to our outpatient clinic with localized left upper quadrant (LUQ) pain since 5 months earlier. Intermittent attacks of abdominal pain that progressed to a constant pain and eventually led to shortness of breath were reported.

She had no complaints of fever, weight loss, dyspnea, nausea, vomiting, and altered bowel habits. There was no history of abdominal trauma or surgery. Her medical history was negative and physical examination was unremarkable. All laboratory tests were normal and serological test had no evidence of parasitic infection with echinococcusgranulosus.

Plain abdominal radiography was normal. Ultrasound examination showed splenomegaly and hypoechoic well defined intrasplenic cystic lesion.

Computed tomography revealed a cystic mass-like lesion measuring about $25 \times 13 \times 12 \mathrm{~cm}$ with internal septa in the spleen with a rim of remaining splenic parenchyma, which displaced pancreatic tail and body to the right side with mild pressure effect on the stomach (figure 1).

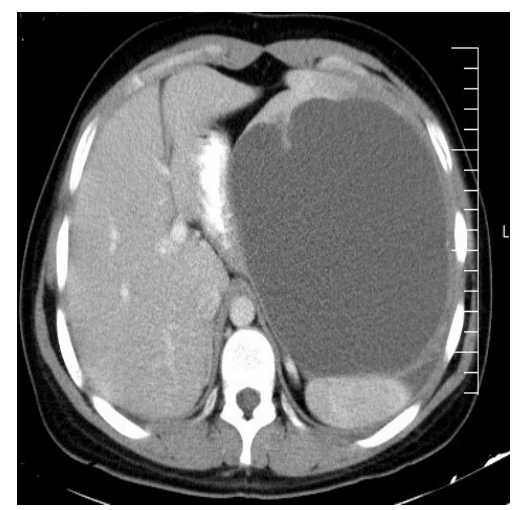

Fig.1: Computed tomogram shows a large cystic lesion in the spleen (axial view)

\section{What is your diagnosis? \\ Answer:}

\section{Epithelial (mesothelial) cyst}

The diagnosis of a splenic cyst was confirmed and after pneumococcal vaccination, laparotomy-splenectomy was performed. A large cystic mass was detected with displacement of total remaining splenic parenchyma. Spleen with the cyst was sent for pathological examination. On gross exam the cyst was filled with yellowish clear fluid. In microscopic evaluation (figure 2), fibrous cyst wall was partially lined by flat to cuboidal bland looking cells. In immunohistochemical evaluation,the cells were positive for cytokeratin and calretinin. The surrounding spleen showed sinus dilation, fibrosis of red pulp and accumulation 

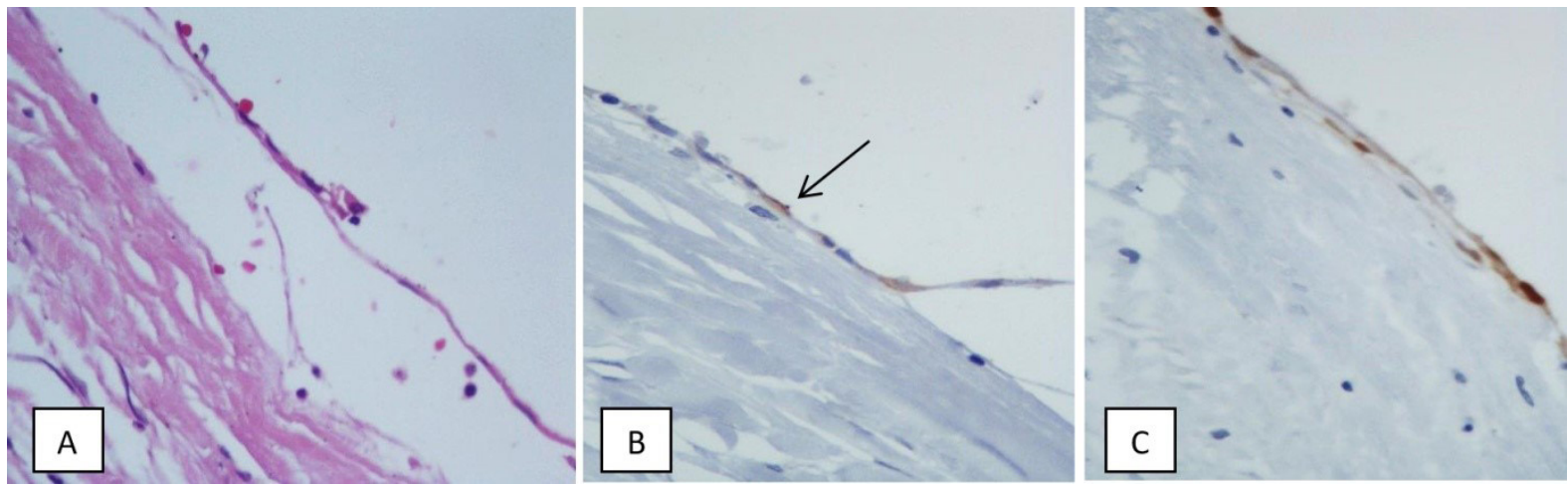

Fig.2: (A) Fibrous cyst wall lined by flat epithelial cells. (B) Positive reaction for cytokeratin (arrow). (C) Positive reaction of flat lining cells for calretinin

of hemosiderin laden macrophages. Lymphoid follicles were rather inconspicuous. The final pathological diagnosis was epithelial (mesothelial) cyst of spleen. During admission, no complication occurred.

\section{DISCUSSION}

Splenic cysts are rare findings (incidence is 0.75 per $100,000)$ and usually asymptomatic. They are incidentally found during ultrasonography or other imaging modalities. ${ }^{1}$ They can be classified as true or false cysts depending on whether they have an epithelial lining layer. True cysts can be either congenital or acquired. False cysts or pseudocysts of the spleen originate from traumatic injury, hemorrhage, infection, and infarction. ${ }^{2,3}$

The main differential diagnoses of acquired splenic cyst are parasitic disease, epidermoid/epithelial cyst, dermoid cyst, hemangioma, and/or lymphangioma. Congenital splenic cysts are called epithelial or epidermoid. ${ }^{3}$ They are mainly primary non-parasitic splenic cysts (PNSC), and constitute approximately $10 \%$ of the total cysts. These lesions occur most commonly in children and young female patients, and have a good prognosis. ${ }^{2}$ Most of the cysts are asymptomatic and diagnosed incidentally. The symptoms are related to the size of the cyst and its complications such as infection, rupture, and/or bleeding. Patients with large splenic cysts may complain of early satiety, and LUQ discomfort or pain. Sometimes large cysts lead to splenomegaly, which causes dyspnea, shoulder pain, and constipation due to pressure effect on adjacent visceral organs. The most serious complication of large splenic cyst is spontaneous or traumatic rupture leading to life threatening intra-abdominal hemorrhage. ${ }^{4}$ The patient's history (age, sex, history of trauma, and duration of symptoms) may be helpful in some cases to determine the etiology of the cyst. ${ }^{5}$

The indication for treatment is not clear and depends on the size and nature of the cyst and symptoms. Large cysts have tendency to develop serious complications such as rapture, so they are candidate for surgery.

Cysts larger than $5 \mathrm{~cm}$ are at risk of rupture and have a low probability of spontaneous recovery. Therefore, their treatment is absolutely necessary and laparoscopy/ laparotomy splenectomy is the method of choice. ${ }^{6-8}$

\section{CONFLICT OF INTEREST}

The authors declare no conflict of interest related to this work.

\section{REFERENCES}

1. Belekar D, Desai A, Dewoolkar A, Dewoolkar V, Bhutala U. Splenic epithelial cyst: A rare entity. Int J Surg 2010;22:1-8.

2. Cianci P, Tartaglia N, Altamura A, Fersini A, Vovola F, Sanguedolce F, et al. A recurrent epidermoid cyst of the spleen: report of a case and literature review. World J Surg oncology 2016;14:1. doi:10.1186/s12957-016-0857-x.

3. Mirilas P, Mentessidou A, Skandalakis JE. Splenic cysts: are there so many types? J Am Coll Surg 2007;204:45965. doi: 10.1016/j.jamcollsurg.2006.12.012.

4. Fragandreas G, Papadopoulos S, Gerogiannis I, Spyridis C, Tsantilas D, Venizelos I, et al. Epithelial splenic cysts and lifethreatening splenic rupture. Chirurgia (Bucur) 2011;106:519-22.

5. Morgenstern L. Nonparasitic splenic cysts: pathogenesis, classification, and treatment. $J$ Am Coll Surg 2002;194:306-14. doi:10.1016/S1072-7515(01)01178-4.

6. Surlin V, Georgescu E, Râmboiu S, Dumitrescu C, Bratiloveanu T, Georgescu I. Large splenic cysts at the upper pole of the spleen-laparoscopic management. $J$ De Chirurgie 2011;7:93-100.

7. Macheras A, Misiakos EP, Liakakos T, Mpistarakis D, Fotiadis C, Karatzas G. Non-parasitic splenic cysts: a report of three cases. World J Gastroenterol 2005;11:68847. doi: 10.3748/wjg.v11.i43.6884.

8. Palmieri I, Natale E, Crafa F, Cavallaro A, Mingazzini Pl. Epithelial splenic cysts. Anticancer Res 2005;25:515-21. 